\title{
Pharmacists' Knowledge, Perception and Practice on Antibiotic Stewardship: A Survey in Indonesia
}

\author{
Heni Lutfiyati ${ }^{1}$, Zullies Ikawati ${ }^{2}$, Jarir Atthobari ${ }^{3}$, Nanang Munif Yasin ${ }^{4}$ \\ \{zulliesikawati@ugm.ac.id²\} \\ Doctoral Program in Pharmaceutical Sciences, Faculty of Pharmacy, Universitas Gadjah Mada, \\ Yogyakarta, Indonesia ${ }^{1}$ \\ Department of Pharmacy, Faculty of Health Science, Universitas Muhammadiyah Magelang, Magelang, \\ Indonesia ${ }^{1}$ \\ Department of Pharmacology and Clinical Pharmacy, Faculty of Pharmacy, Universitas Gadjah Mada, \\ Yogyakarta, Indonesia ${ }^{2,4}$ \\ Clinical Epidemiology and Biostatistic Unit, FMPHN, Universitas Gadjah Mada, Yogyakarta, Indonesia ${ }^{3}$ \\ Department of Pharmacology and Therapy, FMPHN, Universitas Gadjah Mada, Yogyakarta, Indonesia ${ }^{3}$
}

\begin{abstract}
Antimicrobial resistance has become a world health problem, with various detrimental effects that can reduce the quality of health services. The contribution of Pharmacists in antibiotic control has been proven effective, therefore pharmacists need to expand their role to be directly involved in patient care. This study aims to evaluate the knowledge, perceptions and practices of pharmacists in antibiotic stewardship. The study used cross-sectional design by collecting data in August-September 2020 from pharmacists. The data were analyzed using the Mann-Whitney and Kruskal-Wallis test with SPSS version 20.0. 186 pharmacist average score of knowledge $4.25 \pm 0.39$, perception $4.32 \pm 0.38$ and practice $42.96 \pm 6.36$. Results showed that $59.68 \%$ have good knowledge, $79.57 \%$ good perception and $99.46 \%$ good practiced on antibiotic stewardship. The Mann Whitney test showed a significant difference on the level of knowledge based on education level and the Kruskal-Wallis test showed a significant difference on the level of knowledge, perception and practice by workplace. Most of the pharmacist have good knowledge, perception and practice about antibiotic stewardship.
\end{abstract}

Keywords: Pharmacists, knowledge, perception, practice, antibiotic stewardship

\section{Introduction}

The data on the rational use of Indonesian antibiotics are still limited. The result of the study, entitled "Antimicrobial Resistance in Indonesia, Prevalence and Prevention [1]" indicates the problem of antimicrobial resistance, namely the use of antibiotics that is not wise, and controls that have not been implemented properly. The result of the AMRIN research team at 2 teaching hospitals in Indonesia shows that only $21 \%$ of antibiotic prescriptions are rational [2], and it also results in recommendations in the form of validated methods to control bacterial resistance efficiently and according to the standard. Through the Indonesian Ministry of Health, the results of these studies are disseminated throughout hospitals in Indonesia, with the hope that the results of these recommendations can be carried out immediately [1].

Misuse, overuse and underuse of antibiotics are the main causes of the emergence of resistant microbes [3]. Antimicrobial resistance has become a world health problem, with 
various detrimental effects that can reduce the quality of health services. The growth and development of antimicrobial resistance occur because of the selection process related to the use and spread of antibiotics. The selection process can be inhibited by increasing the use of antibiotics wisely, while the spread process can be inhibited by implementing infection control (standard precautions) correctly [4].

WHO in 2015 developed a "Global Action Plan On Antimicrobial Resistance" [5]. Most countries are pursuing strategies to overcome the increase in antimicrobial resistance, both individuals, government agencies or agencies and between institutions from one country to another with the "Antimicrobial Stewardship Program".

Evaluation of drug use is one of the pharmacists' duties in providing added value and increasing the pharmacist's role in the health service system. (AMCP, 2004). Evaluation of the quality of antibiotic use is carried out to determine the antibiotic use policy. Gyssens et al., developed an evaluation of antibiotic use to assess the appropriateness of antibiotic use such as; the accuracy of indication, the accuracy of antibiotic selection based on effectiveness, toxicity, price and spectrum, duration of administration, dose, interval, route, and time of administration [6]

The study MacMillan MK, 2019 [7] shows the impact of involving pharmacists in the Antimicrobial Resistance Control Program, that is the use of antimicrobials becomes rational and more efficient in-patient follow-up. The pharmacist's role has an impact on reducing inappropriate antimicrobial regimens, optimizing prescriber behaviour, monitoring antimicrobial use, preventing infection incidence, advising doctors, educating all health workers, and helping to develop policies [8]. The contribution of pharmacists in antibiotic control has been proven effective, therefore pharmacists need to expand their role to be directly involved in patient care such as modification of intravenous care to oral and Automatic Stop Orders which can improve patient care [9]. Various campaigns to control antibiotic resistance have been carried out but not many research has been found on the knowledge, perceptions and practices of pharmacists in controlling antimicrobial resistance programs. Based on the above background, the researchers considered it necessary to know the knowledge, perceptions and practices of pharmacists in controlling the use of antibiotics.

\section{Method}

This study is a preliminary study prior to the development of an intervention model for the Automatic Stop Order of antibiotics in hospitals. This type of research is non-experimental with a descriptive survey design. The data collection involves pharmacists in September-October 2020. The research subjects are pharmacists who practice in pharmaceutical services. Data collection activities begin after the research protocol has obtained ethical clearance from the Research Ethics Commission of the Faculty of Medicine, Gadjah Mada University, Yogyakarta.

The editing process includes the checking of the data completeness, then grouped by respondents' answers. The questionnaire is adopted from [10] which has been translated into Indonesian. The questionnaire provided is validated by sending 2 experts to ask for related opinions about the relativity and importance of the content. The necessary improvements are made to the questionnaire before it is given to the respondent. The reliability coefficient of the data obtained was calculated using SPSS v. 20 with a Cronbach alpha value of 0.637 for knowledge, 0.741 for perception and 0.709 for practice.

The questionnaire has 32 question items and is divided into 4 sections 
1. Characteristic of the pharmacist that consists of 5 questions

2. Knowledge that consists of 8 questions,

3. The pharmacist's perception that consists of 8 questions

The rating scale for knowledge and perception uses a 5-point Likert scale. The scores are 1 $=$ strongly disagree, $2=$ disagree, $3=$ neutral, $4=$ agree, and $5=$ strongly agree .

4. The pharmacist practice consists of 11 questions. The scores are $1=$ never, $2=$ rarely, 3 $=$ sometimes, $4=$ often, and $5=$ always.

The overall score of knowledge, perception and practice is carried out in such a way that $0.5-1$ is defined as "very bad", 1.5-2 "bad", 2.5-3 "acceptable", 3.5-4 "good", and 4.5-5 "very good ". Practice-related outcomes are defined as "good" versus "bad." For practice, a score $\geq 28$ is considered good, and a score $<28$ is considered bad.

The data is analyzed using SPSS v.20. Descriptive analysis is used to display data. The data normality test uses the Kolmogorov-Smirnov test. Inferential statistics (Mann-Whitney and Kruskal-Wallis tests) are used to see the difference in scores due to abnormal data distribution. The p-value is less than 0.05 , which means statistically significant.

\section{Result and Discussion}

A total of 186 respondents are all pharmacists. Most of them are female (81.2\%) in the age of $25-45$ years $(86.6 \%)$, and have pharmacist degree $(81.7 \%)$ responded to this survey. Most of the respondents $(57 \%)$ have been working less than 5 years and $57 \%$ of the pharmacists' work in a pharmacy. Sociodemographic profiles of the respondents are provided in Table 1.

Table 1. Characteristic of pharmacist $(\mathrm{N}=186)$

\begin{tabular}{llll}
\hline Characteristic & Categories & Frequences & $\%$ \\
\hline Gender & Female & 151 & 81.2 \\
& Male & 35 & 18.8 \\
\hline Age & $<25$ years & 14 & 4.5 \\
& $25-35$ years & 87 & 39.8 \\
& $36-45$ years & 74 & 5.9 \\
\hline Education & 46-55 years & 11 & 81.7 \\
& Pharmacist degree & 152 & 18.3 \\
\hline Works experience & Master degree & 34 & 34.4 \\
& $<5$ years & 64 & 31.2 \\
& $5-10$ years & 58 & 0 \\
& $11-15$ years & 0 & 10.2 \\
& $16-20$ years & 19 & 24.2 \\
\hline Workplace & $>20$ years & 45 & 57 \\
& Pharmacies & 106 & 30.1 \\
& Community health centers, & 11 & 5.9 \\
& Hospitals & 56 & 7.0 \\
\hline
\end{tabular}




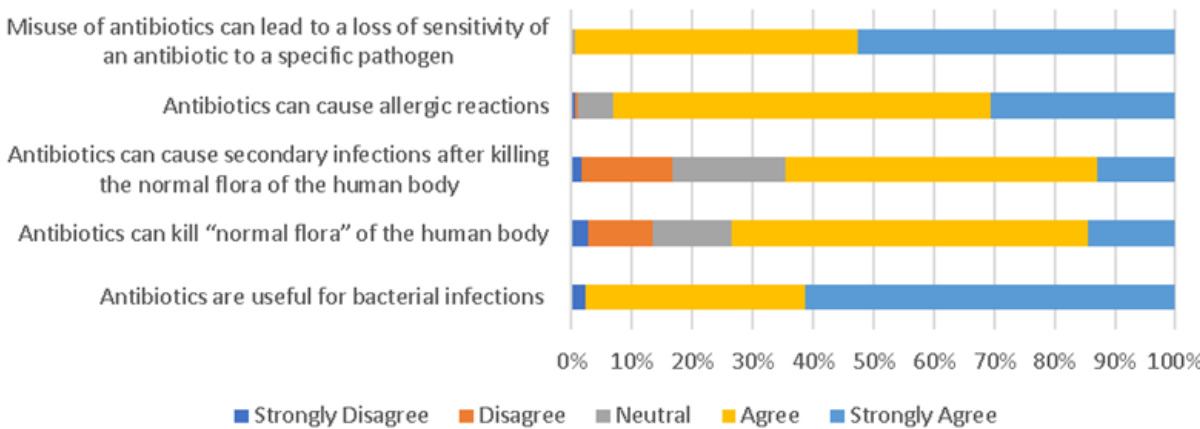

$\begin{array}{llllllllllll}0 & 0 & 10 \% & 20 \% & 30 \% & 40 \% & 50 \% & 60 \% & 70 \% & 80 \% & 90 \% & 100 \%\end{array}$

a Strongly Disagree $=$ Disagree $=$ Neutral $=$ Agree $=$ Strongly Agree

Fig. 1. Responses of pharmacist regarding knowledge about antibiotic stewardship (Question Favorable)

A total of 186 respondents has responded to 8 questions about their knowledge on antibiotic stewardship. From the maximum score of knowledge about antibiotic stewardship of 5, it is obtained that respondents have an average score of $4.25 \pm 0.39$. Therefore, respondents have good knowledge of antibiotic stewardship. A total of $182(97.9 \%)$ participants strongly agree /agree that "Antibiotics are useful for bacterial infections". as much as $89.8 \%(\mathrm{n}=167)$ participants strongly agree/agree that "Antibiotics can kill the 'normal flora' of the human body. For details on respondents' answers to questions that support their knowledge of antibiotic stewardship can be seen in Figure 1.

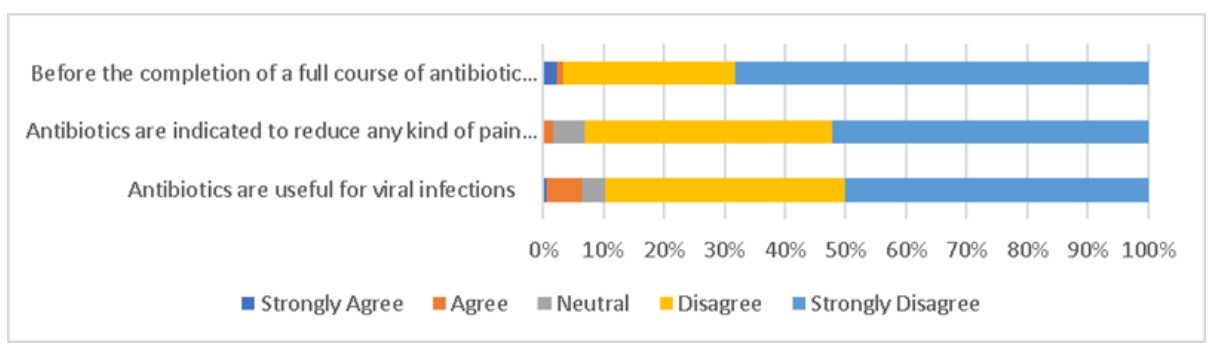

Fig. 2. Responses of pharmacist regarding knowledge about antibiotic stewardship (Question Unfavourable)

Respondents' responses to unfavourable questions, as many as 137 (73.6\%) participants strongly disagree that "Antibiotics are useful for viral infections". The details of respondents' answers to unfavourable questions about knowledge of antibiotic stewardship can be seen in Figure 2. 


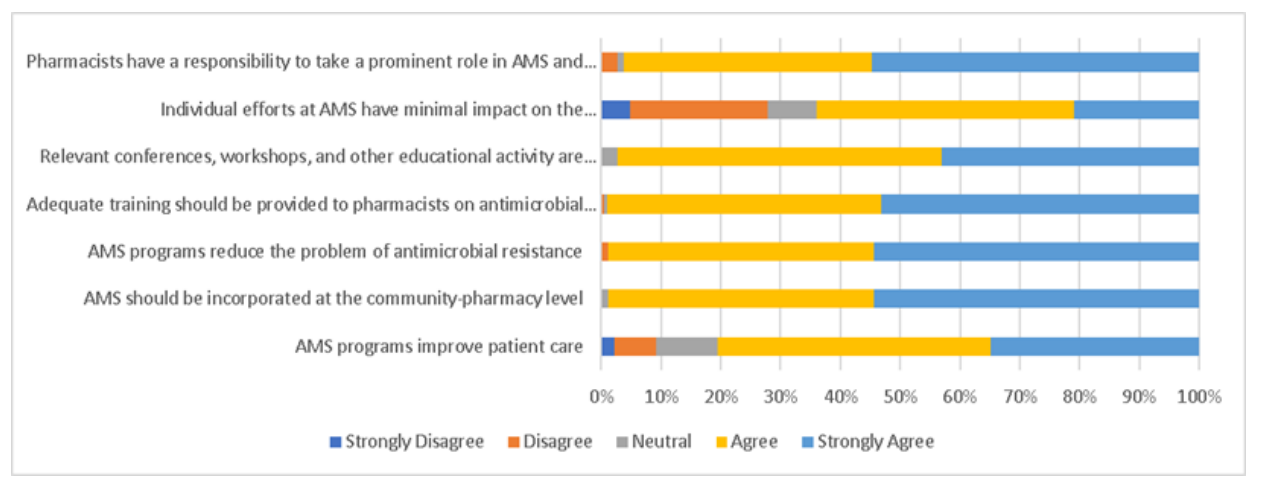

Fig. 3. Responses of pharmacist regarding perception about antibiotic stewardship (Question Favorable)

All respondents have responded to 8 questions about their perceptions of AMS. From a maximum score of $5(100 \%)$, for the perception of AMS, the average respondent score is 4.32 \pm 0.38 . Respondents stated that they have positive perceptions about AMS. All participants strongly agree that "AMS program reduces the problem of antimicrobial resistance and should be incorporated at the community-pharmacy level. The details of respondents' answers to questions that support their perception of antibiotic stewardship can be seen in Figure 3.

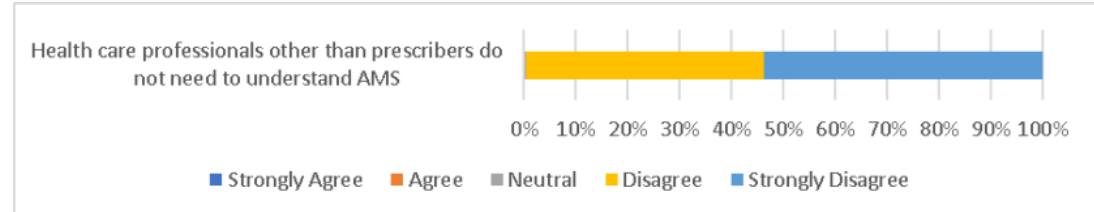

Fig. 4. Responses of pharmacist regarding perception about antibiotic stewardship (Question Unfavorable)

All respondents strongly disagree that Health care professionals other than prescribers do not need to understand AMS

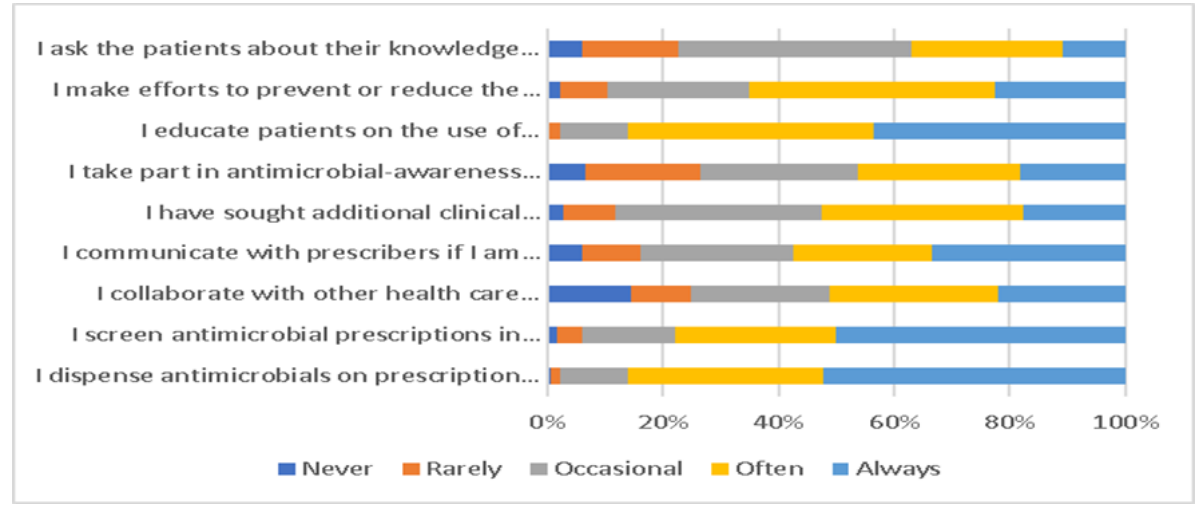

Fig. 5. Responses of pharmacist regarding practice antibiotic stewardship (Question Favorable) 
All respondents responded to all statements about their practice at AMS. A maximum score is $55(100 \%)$, the respondents obtain an average score of $42.96 \pm 6.36$. Therefore, the respondents show good results practice about AMS: $86.1 \%(n=160)$ of respondents dispense antimicrobials on prescriptions with complete clinical information. Details of Respondents' responses can be seen in Figure 5

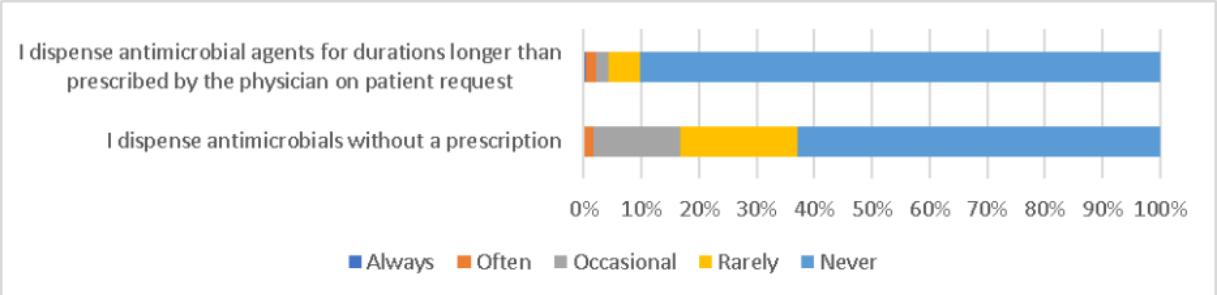

Fig. 6. Responses of pharmacist regarding practice antibiotic stewardship (Question Unfavorable)

$83.3 \%(\mathrm{n}=155)$ of the participants never / rarely dispense antimicrobial without prescriptions and $95.7 \%(n=178)$ of them never/ rarely dispense antimicrobial agents for longer than the durations prescribed by the physician on patient request.

This study evaluates the knowledge, perceptions and practices of pharmacists in antibiotic stewardship. The results show that $39.78 \%$ of pharmacists have very good knowledge of antibiotic stewardship, $59.68 \%$ is good and $0.54 \%$ is acceptable. The pharmacist's perception of stewardship antibiotics is very good $14.52 \%, 79.57 \%$ is good and $5.91 \%$ is acceptable. Most of the pharmacists $(99.46 \%)$ practice well on antibiotic stewardship. Pharmacists have a lot to do with problems about antimicrobial resistance and antimicrobial stewardship and more willingness to participate in antimicrobial stewardship interventions in the hospital (11)

Pharmacists in Pakistan have positive knowledge and practice towards AMS. Implementation of the AMS program is needed in Pakistan and pharmacists play an important role in it by enhancing and updating their knowledge according to the current guidelines with ongoing training and professional development programs. Pharmacists and other healthcare professionals should work together in multi-disciplinary teams to reduce antimicrobial risk resistance, to reduce the economic burden, to improve patient quality of life, and to reduce the length of stay due to infection (12)

Research on the knowledge, perceptions and practices of pharmacists in antibiotic stewardship has not been widely studied. Most of the research use community pharmacy respondents. Pakistani research of Community Pharmacists shows that community pharmacists are well-versed in antibiotics. There are some internal flaws Perceptions and practices of community pharmacists about AMS (10). The pharmacy community has a positive perception of antibiotic stealth but they feel they need training, anti-microbial stewardship guidelines and a collaborative GP-CP system to improve their practice (13). Portuguese pharmacists understand that the use of antibiotics and bacterial resistance can be improved by changing behaviour related to antibiotics (14). The Minister of Health of the Republic of Indonesia has published general guidelines for the use of antibiotics and guidelines for pharmaceutical services for antibiotic therapy so that pharmacists can refer to these guidelines in carrying out their practice (15) (16) 
Table 2. Pharmacists' knowledge, perceptions, and practices regarding antibiotic stewardship based on the characteristics of the respondents

\begin{tabular}{|c|c|c|c|c|c|c|c|}
\hline \multirow[t]{2}{*}{ Variable } & \multirow[t]{2}{*}{ Categories } & \multicolumn{2}{|l|}{ Knowledge } & \multicolumn{2}{|l|}{ Perception } & \multicolumn{2}{|l|}{ Practices } \\
\hline & & Mean \pm SD & $\begin{array}{l}\mathrm{P}- \\
\text { value }\end{array}$ & Mean \pm SD & $\begin{array}{l}\mathrm{P} \text { - } \\
\text { value }\end{array}$ & Mean \pm SD & P-value \\
\hline \multirow[t]{2}{*}{ Gender } & Female & $4.25 \pm 0.40$ & 0.782 & $4.31 \pm 0.38$ & 0.775 & $42.88 \pm 6.4$ & 0.748 \\
\hline & Male & $4.23 \pm 0.35$ & & $4.34 \pm 0.35$ & & $43.31 \pm 6.16$ & \\
\hline \multirow[t]{4}{*}{ Age } & $<25$ years & $4.27 \pm 0.27$ & 0.907 & $4.33 \pm 0.32$ & 0.775 & $38.85 \pm 5.84$ & 0.070 \\
\hline & $25-35$ years & $4.23 \pm 0.38$ & & $4.31 \pm 0.38$ & & $43.25 \pm 6.53$ & \\
\hline & $36-45$ years & $4.26 \pm 0.43$ & & $4.35 \pm 0.39$ & & $43.19 \pm 6.41$ & \\
\hline & $46-55$ years & $4.24 \pm 0.39$ & & $4.22 \pm 0.37$ & & $44.36 \pm 3.26$ & \\
\hline \multirow[t]{2}{*}{ Education } & $\begin{array}{l}\text { Pharmacist } \\
\text { degree }\end{array}$ & $4.21 \pm 0.39$ & 0.025 & $4.31 \pm 0.37$ & 0.934 & $42.88 \pm 6.35$ & 0.509 \\
\hline & Master degree & $4.39 \pm 0.36$ & & $4.33 \pm 0.38$ & & $43.59 \pm 6.46$ & \\
\hline Works & $<5$ years & $4.26 \pm 0.37$ & 0.817 & $4.33 \pm 0.37$ & 0.638 & $42.73 \pm 6.79$ & 0.324 \\
\hline \multirow{4}{*}{$\begin{array}{l}\text { Expe- } \\
\text { rience }\end{array}$} & $5-10$ years & $4.26 \pm 0.39$ & & $4.29 \pm 0.35$ & & $41.91 \pm 6.49$ & \\
\hline & $11-15$ years & 0 & & 0 & & 0 & \\
\hline & $16-20$ years & $4.15 \pm 0.50$ & & $4.30 \pm 0.33$ & & $44.37 \pm 6.47$ & \\
\hline & $>20$ years & $4.26 \pm 0.38$ & & $4.37 \pm 0.43$ & & $44.04 \pm 5.39$ & \\
\hline \multirow{4}{*}{$\begin{array}{l}\text { Work- } \\
\text { place }\end{array}$} & Pharmacies & $4.21 \pm 0.39$ & 0.017 & $4.26 \pm 0.38$ & 0.004 & $41.71 \pm 6.27$ & 0.010 \\
\hline & $\begin{array}{l}\text { Community } \\
\text { health centers, }\end{array}$ & $4.32 \pm 0.38$ & & $4.50 \pm 0.36$ & & $44.96 \pm 6.16$ & \\
\hline & Hospitals & $3.99 \pm 0.38$ & & $4.16 \pm 0.23$ & & $44.27 \pm 5.44$ & \\
\hline & Clinics & $4.42 \pm 0.39$ & & $4.43 \pm 0.36$ & & $43.38 \pm 6.91$ & \\
\hline
\end{tabular}

The mean in knowledge, perceptions and practices regarding antibiotic services is analyzed. Based on the Mann-Whitney test, the independent samples show no statistically significant difference ( $p>0.05)$ between scores of pharmacists' knowledge, perceptions and practice in antibiotic services. Meanwhile, the education level shows a statistically significant difference (P> 0.05) in knowledge level score. Educated pharmacists have a higher knowledge score (P $<0.05)$ versus pharmacists with a bachelor's degree. The results of the independent sample Kruskal-Wallis test, age and work experience, score of knowledge, perception and practice of pharmacists do not have a statistically significant difference. ( $P>0.05)$. Work place shows statistically significant differences $(\mathrm{p}<0.05)$ in pharmacist knowledge, attitudes and practice in antibiotic surveillance.

According to the Association of American Health-System Pharmacists (ASHP) pharmacists have a responsibility to play an important role in antimicrobial stewardship programs and participate in infection prevention and control programs. The pharmacist's responsibility for antimicrobial stewardship and infection prevention and control includes promoting rational antimicrobial use, reducing infection transmission, and education of health professionals, patients and the public (17). The role of the Pharmacist has an impact on reducing antimicrobial regimens that are not suitable through various AMS strategies, optimizing prescriber behaviour, monitoring antimicrobial use, prevention of infection incidence and education, training and public involvement (8). 
Based on the level of knowledge, there is a significant difference between pharmacists with a master degree and a bachelor degree. Pharmacists with a master degree have a higher knowledge score than those with a bachelor degree. The higher the pharmacist's education level, the better the knowledge level. Pharm D students know more about antibiotic use and resistance than B Pharm students who lack of accurate information. Therefore, it is necessary to educate B Pharm students so that they can apply the knowledge gained during education in their practice (18). Pharmacists in Malaysia who have postgraduate qualifications are more likely to have a positive perception of antimicrobial stewardship than non-postgraduate pharmacists (19). The study (20) concludes that a continuous effort is needed to improve pharmacist skills by adding more materials on infectious diseases to the curriculum and adding AMS training. Pharmacists are a core team of AMS which need continuing education that is in line with practical realities. In Indonesia, Indonesian Pharmacists Association (IAI) has implemented Continuing Professional Development (CPD) to refresh and update the knowledge of practising pharmacists.

Based on the workplace, there are significant differences in scores of pharmacists' knowledge, perceptions and practice of antibiotic stewardship. Pharmacists who work in hospitals have the lowest knowledge and perception scores compared to pharmacists who work in pharmacies, public health centres and clinics while pharmacists who work in pharmacies have the lowest practice score than pharmacists who work in other pharmaceutical service facilities. Because there are still many pharmacists in hospitals who have never attended training in antimicrobial stewardship. Based on the Minister of Health regulation no. 8 of 2015 concerning Antimicrobial Stewardship Program, each hospital must carry out Antimicrobial Stewardship Program optimally, so that pharmacists who practice in several hospitals have become the members of the Antimicrobial Stewardship Program team (21).

\section{Conclusion}

Most Pharmacists in Indonesia have knowledge, perceptions and good practice of pharmacists. 186 pharmacist average score of knowledge $4.25 \pm 0.39$, perception $4.32 \pm 0.38$ and practice $42.96 \pm 6.36$. Results showed that $59.68 \%$ have good knowledge, $79.57 \%$ good perception and $99.46 \%$ good practiced on antibiotic stewardship. The Mann Whitney test showed a significant difference on the level of knowledge based on education level and the Kruskal-Wallis test showed a significant difference on the level of knowledge, perception and practice by workplace.

\section{References}

[1] Amrin Study G. Antimicrobial resistance, antibiotic usage and infection cntrol. A self-assessment program for Indonesian hospitals. Jakarta: Direktorat Jendral Pelayanan Medis. 2005;17-25.

[2] Hadi U, Duerink DO, Lestari ES, Nagelkerke NJ, Werter S, Keuter M, et al. Survey of antibiotic use of individuals visiting public healthcare facilities in Indonesia. International Journal of Infectious Diseases. 2008;12(6):622-629.

[3] Tenover FC. Mechanisms of antimicrobial resistance in bacteria. The American journal of medicine. 2006;119(6):S3-S10.

[4] Hadi U, Duerink DO, Lestari ES, Nagelkerke NJ, Keuter M, In't Veld DH, et al. Audit of antibiotic prescribing in two governmental teaching hospitals in Indonesia. Clinical microbiology and infection. 2008;14(7):698-707. 
[5] World Health Organization. Global Action Plan On Antimicrobial Resistance [Internet]. 2015. Available

from:

http://www.wpro.who.int/entity/drug_resistance/resources/global_action_plan_eng.pdf

[6] Gyssens IC. Quality measures of antimicrobial drug use. International journal of antimicrobial agents. 2001;17(1):9-19.

[7] MacMillan KM, MacInnis M, Fitzpatrick E, Hurley KF, MacPhee S, Matheson K, et al. Evaluation of a pharmacist-led antimicrobial stewardship service in a pediatric emergency department. International journal of clinical pharmacy. 2019;1-7.

[8] Messina AP, van den Bergh D, Goff DA. Antimicrobial Stewardship with Pharmacist Intervention Improves Timeliness of Antimicrobials Across Thirty-three Hospitals in South Africa. Infect Dis Ther. 2015 Sep 1;4(1):5-14.

[9] Weller TMA, Jamieson CE. The expanding role of the antibiotic pharmacist. Journal of Antimicrobial Chemotherapy. 2004;54(2):295-298.

[10] Sarwar MR, Saqib A, Iftikhar S, Sadiq T. Knowledge of community pharmacists about antibiotics, and their perceptions and practices regarding antimicrobial stewardship: a cross-sectional study in Punjab, Pakistan. Infection and drug resistance. 2018;11:133.

[11] Cotta MO, Robertson MS, Tacey M, Marshall C, Thursky KA, Liew D, et al. Attitudes towards antimicrobial stewardship: results from a large private hospital in Australia. Healthcare infection. 2014;19(3):89-94.

[12] Rehman IU, Asad MM, Bukhsh A, Ali Z, Ata H, Dujaili JA, et al. Knowledge and practice of pharmacists toward antimicrobial stewardship in Pakistan. Pharmacy. 2018;6(4):116.

[13] Saha SK, Barton C, Promite S, Mazza D. Knowledge, Perceptions and Practices of Community Pharmacists Towards Antimicrobial Stewardship: A Systematic Scoping Review. Antibiotics. 2019;8(4):263.

[14] Roque F, Soares S, Breitenfeld L, López-Durán A, Figueiras A, Herdeiro MT. Attitudes of community pharmacists to antibiotic dispensing and microbial resistance: a qualitative study in Portugal. International journal of clinical pharmacy. 2013;35(3):417-424.

[15] Kemenkes RI. Pedoman umum penggunaan antibiotik. Jakarta: Kementerian Kesehatan Republik Indonesia. 2011;

[16] Kemenkes RI. Pedoman pelayanan kefarmasian untuk terapi Antibiotik. Jakarta: Depkes RI. 2011;

[17] Pedersen CA, Schneider PJ, Scheckelhoff DJ. ASHP national survey of pharmacy practice in hospital settings: Prescribing and transcribing - 2010. American Journal of Health-System Pharmacy. 2011;68(8):669-88.

[18] Ahmad A, Khan MU, Moorthy J, Jamshed SQ, Patel I. Comparison of knowledge and attitudes about antibiotics and resistance, and antibiotics self-practicing between Bachelor of Pharmacy and Doctor of Pharmacy students in Southern India. Pharmacy practice. 2015;13(1).

[19] Khan MU, Hassali MAA, Ahmad A, Elkalmi RM, Zaidi STR, Dhingra S. Perceptions and practices of community pharmacists towards antimicrobial stewardship in the state of Selangor, Malaysia. PloS one. 2016;11(2).

[20] Nasr ZG, Higazy A, Wilbur K. Exploring the gaps between education and pharmacy practice on antimicrobial stewardship: a qualitative study among pharmacists in Qatar. Advances in medical education and practice. 2019;10:287.

[21] Kemenkes. Peraturan Menteri Kesehatan Republik Indonesia Nomor 8 Tahun 2015 Tentang Program Pengendalian Resistensi Antimikroba di Rumah Sakit [Internet]. 2015. Available from: http://ditjenpp.kemenkumham.go.id/arsip/bn/2015/bn334-2015.pdf 